2009-10-01

\title{
Water bathing alters the speed-accuracy trade-off of escape flights in European starlings
}

\section{Brilot, BO}

http://hdl.handle.net/10026.1/3004

\subsection{6/j.anbehav.2009.07.022}

Animal Behaviour

All content in PEARL is protected by copyright law. Author manuscripts are made available in accordance with publisher policies. Please cite only the published version using the details provided on the item record or document. In the absence of an open licence (e.g. Creative Commons), permissions for further reuse of content should be sought from the publisher or author. 


\section{escape flights in European starlings}

3 Ben O. Brilot ${ }^{\mathrm{a},}{ }^{\text {, }}$, Lucy Asher ${ }^{\mathrm{b}, 1}$ and Melissa Bateson ${ }^{\mathrm{a}}$

4

$5{ }^{\mathrm{a} C e n t r e}$ for Behaviour and Evolution, Institute of Neuroscience, Newcastle University,

6 U.K.

$7 \quad{ }^{b}$ Epidemiology Division, Royal Veterinary College, Hertfordshire, U.K.

8

$9 *$ Correspondence: B.O. Brilot, Centre for Behaviour and Evolution, Institute of

10 Neuroscience, Newcastle University, Henry Wellcome Building, Framlington Place,

11 Newcastle upon Tyne. NE2 4HH. UK.

12 E-mail address: ben.brilot@ncl.ac.uk

13

$14{ }^{1}$ L. Asher is at the Royal Veterinary College, Northumberland Hall, Hawkshead lane,

15 North Mymms, Hatfield, Hertfordshire. AL9 7TA

16 
17 Birds of most species regularly bathe in water, but the function of this behaviour is

18 unknown. We tested the hypothesis that water bathing is important in feather

19 maintenance, and hence should enhance flight performance. We manipulated European

20 starlings', Sturnus vulgaris, access to bathing water in a 2 × 2 design: birds were housed

21 in aviaries either with or without water baths for a minimum of 3 days (long-term access)

22 before being caught and placed in individual cages either with or without water baths for

23 a further $24 \mathrm{~h}$ (short-term access). We subsequently assessed the speed and accuracy of

24 escape flights through an obstacle course of vertical strings. Birds that had bathed in the

25 short term flew more slowly and hit fewer strings than birds that were deprived of bathing

26 water in the short term, whereas long-term access to bathing water had no significant

27 effect on flight performance. Thus recent access to bathing water alters flight

28 performance by altering the trade-off between escape flight speed and accuracy. We

29 hypothesise that lack of bathing water provision could increase anxiety in captive

30 starlings because of an increase in their perceived vulnerability to predation. This study

31 therefore potentially provides an important functional link between the expression of

32 natural behaviours in captivity and welfare considerations.

34 Keywords:

35 animal welfare;

36 dustbathing;

37 European starling;

38 manoeuvrability;

39 passerine; 
40 Sturnus vulgaris;

41 water bathing.

42 
43 Maintenance behaviour has received very little attention from behavioural biologists,

44 despite forming a significant part of the time budgets of many animals. For example, a

45 comparative study by Cotgreave \& Clayton (1994) found that, across 62 bird species,

46 individuals spent an average of $9.2 \%$ of the day in maintenance behaviours (range 0.3 -

$4725.4 \%$ ). An important element of avian maintenance behaviour involves bathing in water.

48 Birds of the majority of species regularly do so, and follow bathing with bouts of

49 preening and oiling behaviour (Simmons 1964; Slessers 1970). However, in contrast to

50 dustbathing, which has been the subject of extensive welfare-related research in domestic

51 fowl (reviewed in Olsson \& Keeling 2005), there has been little work on water bathing

52 since some early descriptive studies.

53 Various hypotheses have been proposed for the benefits of water bathing.

54 Simmons (1964) suggested that bathing serves to wet the feathers in a controlled fashion

55 that aids the distribution of preen oil and thus enhances preening. In support of this he

56 described observations in waders and grebes of birds wetting the bill prior to preening

57 when no bathing has occurred. Slessers (1970) suggested that bathing serves to squeeze

58 water through the feathers, ensuring that both skin and feather bases are rinsed. In vitro

59 studies show that water has a direct impact on feather structure (Van Rhijn 1977;

60 Elowson 1984), suggesting a different mechanism whereby bathing could affect feathers.

61 Thus, although the precise mechanism is unclear, it seems likely that water bathing has a

62 function in feather maintenance.

63 Some bird species (e.g. most members of the order galliformes, but also others

64 including some passerine species) bathe in dust as an alternative or supplementary

65 substrate to water. Dustbathing is similarly thought to play a role in feather maintenance, 
66 specifically in reducing ectoparasite loads and controlling the lipid content of feathers

67 (Olsson \& Keeling 2005). The latter hypothesis has been experimentally confirmed

68 (Borchelt \& Duncan 1974; Van Liere \& Bokma 1987), resulting in the suggestion that

69 there is an optimal lipid load for feathers that balances the beneficial effects of

70 waterproofing, insulation and improved feather structural integrity against the costs of

71 feather matting and nourishment for ectoparasites. There is some direct evidence that

72 dustbathing in Japanese quail, Coturnix coturnix japonica, has a function in feather

73 maintenance (Healy \& Thomas 1973). Birds given access to dust showed an

74 improvement in feather barb alignment immediately after dustbathing in comparison to a

75 control group denied access to dust.

76 European starlings, Sturnus vulgaris, and the majority of passerines bathe

77 according to the first method described by Slessers (1970, p. 92). That is, they stand in

78 shallow water and immerse themselves through a set pattern of movements involving

79 dipping the head and rolling the body to ensure that water is distributed widely. There is

80 little published information regarding the bathing behaviour (frequency, seasonality, etc.)

81 of starlings, but they are known anecdotally to be enthusiastic bathers, and

82 recommendations for husbandry of starlings in the laboratory include provision of water

83 baths (Hawkins et al. 2001; Asher \& Bateson 2008). Our own observations of captive

84 starlings confirm that they regularly partake in water bathing. Indeed, they commonly do

85 so when their bathing water has been refreshed, even in the presence of a human

86 observer. The current experiment was stimulated by our observation that birds that have

87 just been caught and handled often bathe immediately when released into a cage or aviary

88 containing fresh bathing water. This suggested to us that bathing, and the following 
89 preening routine, might serve a function in repairing feathers disrupted by catching and

90 handling.

91 A direct test of the hypothesis that bathing facilitates feather maintenance is

92 difficult. In order to score feather disruption it is necessary to catch and handle a bird,

93 reversing any benefits of prior bathing. However, since plumage condition is known to

94 affect flight performance in starlings (Swaddle et al. 1996), we hypothesise that poor

95 feather maintenance should translate directly into reduced flight performance. We

96 therefore tested the hypothesis that depriving starlings of the opportunity to water bathe

97 will impair their escape flight performance, as assessed by their speed and accuracy at

98 negotiating an aerial obstacle course. Since flight performance is likely to translate into

99 reduced ability to escape predators or increased tendency to hit obstacles, the fitness

100 consequences of possible effects of bathing on either speed or accuracy of flight are clear

101 (Cuthill \& Guilford 1990; Lima 1993).

102

103

104 METHODS

105

106 Subjects

107 The subjects were 32 (16 male and 16 female) adult European starlings caught from the

108 wild under licence from Natural England. Prior to the experiment, birds were group-

109 housed in two indoor aviaries $(2.4 \times 2.15 \times 2.3 \mathrm{~m})$ with wood chippings covering the

110 floor, dead trees for perching and cover, and shallow trays of water for bathing. The

111 light:dark cycle was $14: 10 \mathrm{~h}$ and the temperature was $16-18^{\circ} \mathrm{C}$. Throughout the 
112 experiment birds were fed a diet of Purina kitten food ad libitum, supplemented with fruit

113 and mealworms (Tenebrio larvae). Our study was approved by the Named Animal Care

114 Welfare Officer at the Instiute of Neuroscience, Newcastle University. Birds were

115 inspected on a daily basis by technical staff and, following completion of our study,

116 received a full health inspection by a veterinarian prior to their release to the wild at the

117 site where they were originally captured.

118

\section{Morphological Measures}

120 Prior to their allocation to the experimental aviaries (see below), birds were captured by

121 hand and several measures were taken. Weight and wing length were measured as

122 described by Redfern \& Clark (2001). It was not possible to weigh the subjects

123 immediately prior to assessing their flight performance because handling would have

124 disrupted any plumage condition advantages that bathing might have conferred. We

125 scored plumage condition by assessing each primary and tail feather as either: complete,

126 abraded, broken, growing or missing (based on Redfern \& Clark 2001).

127 We then allocated subjects to one of three groups on the basis of how many broken

128 and missing feathers were present: group 1: one or no feathers broken, growing or

129 missing; group 2: two to four feathers broken, growing or missing; group 3: more than

130 four feathers broken, growing or missing. Since plumage condition is known to affect

131 flight performance (Swaddle et al. 1996), equal numbers of birds from each feather

132 condition group were allocated to the four experimental groups (see below).

133 All birds' bills were lightly trimmed with nail clippers at this time, since bill

134 morphology affects preening (Clayton et al. 2005). Bill trimming is a recommended 
135 standard husbandry technique in starlings, required to prevent overgrowth of one

136 mandible by the other (Hawkins et al. 2001). For our experiment they were trimmed just

137 enough to ensure that the mandibles were of equal length.

139 Bathing Manipulation

140 We used a 2 × 2 factorial design in which we manipulated both long- and short-term

141 access to bathing water and assessed the effects of this manipulation on flight

142 performance. All birds were allocated to one of two long-term groups: either an aviary

143 with a water bath $(500 \times 400 \times 180 \mathrm{~mm}$ deep $)$ filled to a depth of $25 \mathrm{~mm}(\mathrm{~N}=17)$, or an

144 aviary with no water bath $(\mathrm{N}=15)$. Birds spent a minimum of 3 days in these aviaries.

145 The day before flight performance testing, birds were recaught and transferred to

146 individual cages $(750 \times 450 \times 440 \mathrm{~mm}$ high) located in a separate room. Birds from each

147 long-term access group were allocated to two short-term groups: birds with short-term

148 access to bathing water received a water bath ( $360 \times 255 \times 60 \mathrm{~mm}$ deep) filled to a depth

149 of $25 \mathrm{~mm}(\mathrm{~N}=16)$, whereas birds with no short-term access received an empty tray of

150 the same dimensions $(\mathrm{N}=16)$. Thus each bird fell into one of four possible treatment

151 groups defined by the combination of long- and short-term access to bathing water it

152 received. Although each of the four groups contained an equal number of females $(\mathrm{N}=4$

153 for all), one male was incorrectly allocated causing unequal numbers of males in long-

154 term access groups (no access to water: $\mathrm{N}=3$ males; access to water only in the long-

155 term: $\mathrm{N}=5$ males; access to water only in the short-term: $\mathrm{N}=4$ males; access to water at

156 all times: $\mathrm{N}=4$ males). 
At 0730 hours on the day of flight performance testing, the birds with baths had

158 their baths cleaned and refilled with fresh water to encourage bathing in the $3 \mathrm{~h}$

159 immediately prior to testing. The birds without baths had their empty trays cleaned and

160 returned to match disturbance levels. All 16 birds in the short-term access group bathed in

161 the $3 \mathrm{~h}$ immediately prior to flight performance testing, but were no longer obviously wet

162 or preening by the time testing began at approximately 1030 hours. Immediately prior to

163 testing, each bird was induced to walk into a release cage using differential lighting

164 conditions, and was then transported to the nearby test room. Thus, birds were not

165 handled between the short-term bathing manipulation and flight performance testing.

166 Birds were tested in a random order.

168 Testing Flight Performance

169 We assessed flight performance by releasing birds through an obstacle course of hanging

170 weighted strings, and recording the number of strings hit and the speed of flight (Witter et

171 al. 1994; Balmford et al. 2000; Swaddle \& Lockwood 2003). The test room (Fig. 1)

172 consisted of an acceleration area clear of obstacles followed by the strings. The latter

173 comprised 38 weighted strings hanging from the ceiling, arranged in seven offset rows.

174 The distance between strings within each row $(275 \mathrm{~mm})$ was approximately three-

175 quarters of the wing-span of an adult starling. The exit from the course opened onto a

176 well-lit escape room (5.2 × $2.3 \times 2.35 \mathrm{~m}$ high) containing a dead tree on which birds

177 could perch. The test room was lit only by light from the escape room to encourage the

178 birds to fly towards the escape room on release. 


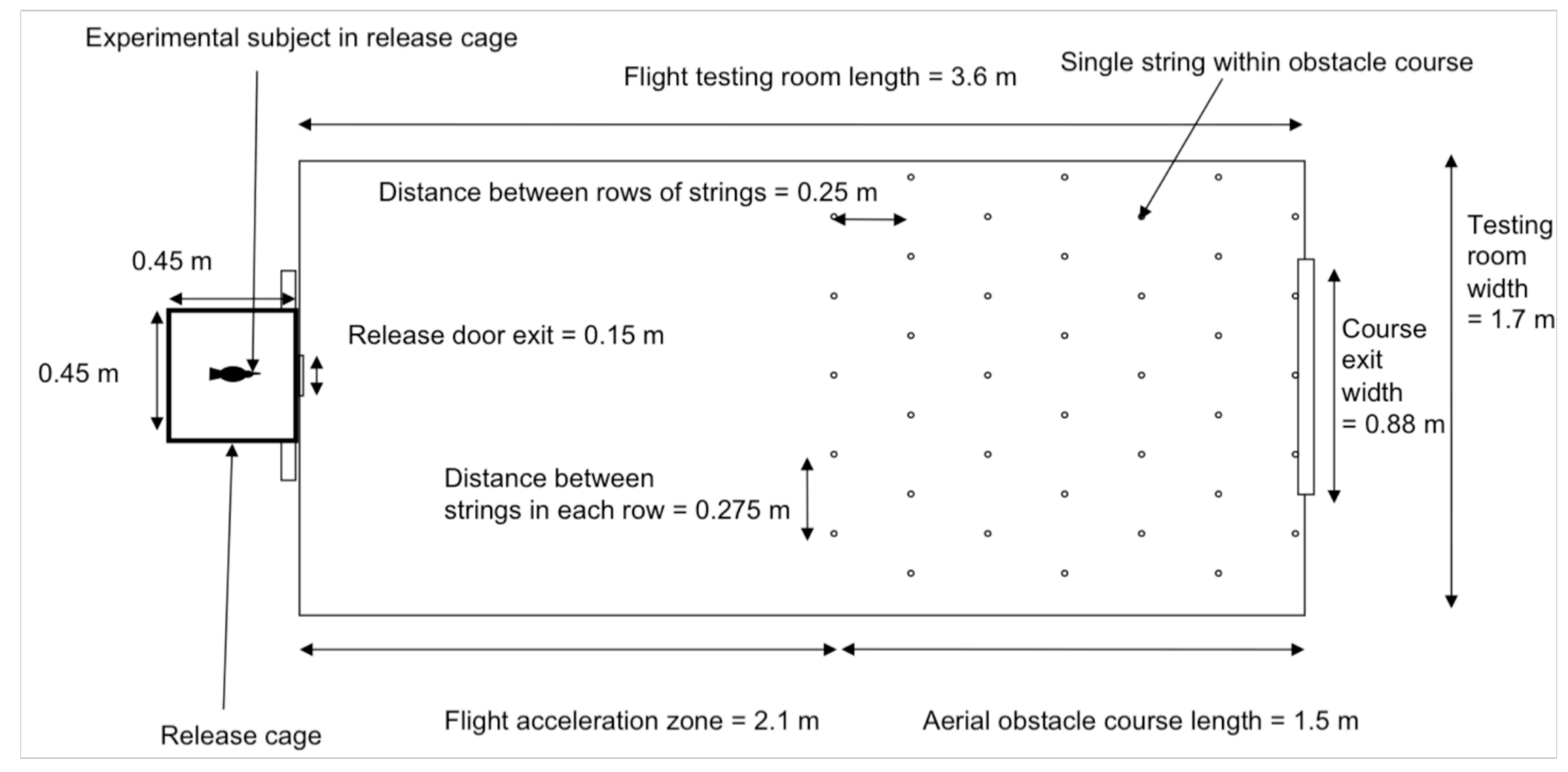

Figure 1. A plan of the test room (approximately to scale). 
A release took place as soon as the bird had settled in a location facing the door of

180 the release cage. We opened the door using a string concurrent with a standardised loud

181 noise (a digitised recording of a bang) played immediately behind the cage from speakers

182 at a constant volume and distance to the bird in the cage. The bird's flight was recorded

183 on a video camera, mounted behind the release cage, running at 30 frames/s, allowing for

184 later frame-by-frame analysis. Another camera mounted vertically above the exit from

185 the test room simultaneously monitored the exit from the release cage (using a mirror)

186 and the exit from the test room.

187 Two measures of flight performance were extracted from the data. We measured

188 flight accuracy by recording the number of strings each bird hit as it negotiated the

189 course. Flight time was calculated as the difference between the time of the frame when

190 the bird passed through the door of the release cage and the time of the frame when its

191 bill breached the exit to the escape room. Flight time was divided by the length of the test

192 room $(3.6 \mathrm{~m})$ to give flight speed $(\mathrm{m} / \mathrm{s})$. All video scoring was conducted blind to the

193 bathing treatment group of the bird.

195 Statistical Analysis

196 We used a MANCOVA to examine the effects of bathing treatment group (short term,

197 long term and their interaction) on our two dependent measures of flight performance

198 (number of strings hit and speed). To refine our selection of covariates, we excluded

199 those that were highly correlated with any that had already been selected for inclusion in

200 the model. Since body weight $(\mathrm{g})$ was significantly correlated with wing length $(\mathrm{mm})\left(r_{31}\right.$

$201=0.535, P=0.002)$ it was the only size-related covariate included. We had six measures 
202 of feather damage: wing or tail feathers missing, broken or abraded. To minimise this

203 number, we grouped any covariates that we had a priori reason to presume would have a

204 similar influence. As previous studies have shown that the absence of feathers (as occurs

205 in moult) can have implications for flight ability (Hedenström 2003), we grouped

206 together the feathers missing and feathers broken variables. However, we chose to group

207 only those measures belonging to the same feather group (wing or tail) since correlations

208 between different measures from the same feather group (wing or tail) were higher than

209 for the same measures from different feather groups. This resulted in four feather

210 measures: wing feathers broken or missing, tail feathers broken or missing, wing feathers

211 abraded and tail feathers abraded. Of these, the number of tail feathers broken or missing

212 was marginally nonsignificantly correlated with weight ( $\tau=0.263, P=0.076$; all other

213 feather variables: $P>0.48$ ); hence only the remaining three feather variables were

214 included with weight as covariates. The interactions between each covariate and separate

215 experimental factor were also initially included in the model. In line with accepted

216 practice we excluded covariates (and their accompanying interactions) in a stepwise

217 manner, removing the least significant term from the model in each step. The covariates

218 were only removed on condition that the interactions with the experimental treatments

219 were also nonsignificant (Engqvist 2005). The number of strings hit was square-root

220 transformed prior to analysis. All assumptions of the performed tests were checked and

221 held true. Estimates of effect size are given in the form of partial Eta squared $\left(\eta_{p}{ }^{2}\right)$ which

222 represents the proportion of the total variance (effect + error) that is attributable to the

223 effect. The weight for one of the subjects was inadvertently not recorded and therefore

224 any analyses conducted where weight was included as a covariate excluded the data from 
225 this subject. Statistical analysis was conducted using SPSS version 16 (SPSS Inc.,

226 Chicago, IL, U.S.A.).

228 RESULTS

229 Our dependent variables were moderately negatively correlated $\left(r_{32}=-0.346, P=0.052\right)$,

230 hence our decision to undertake a multivariate analysis of variance was justified. After

231 we excluded all nonsignificant covariates and interactions, the resulting model included

232 weight as the sole covariate because of the significance of the weight* short-term bathing

233 manipulation interaction (short-term access to bathing water: $V=0.26, F_{2,24}=4.189, P=$

$2340.028, \eta_{p}{ }^{2}=0.26$; long-term access to bathing water: $V=0.01, F_{2,24}=0.128, P=0.881$,

$235 \eta_{p}{ }^{2}=0.01$; interaction between short-term and long-term access to bathing water: $V=$

$2360.07, F_{2,24}=0.927, P=0.410, \eta_{p}{ }^{2}=0.07$; weight: $V=0.12, F_{2,24}=1.633, P=0.216, \eta_{p}{ }^{2}$

$237=0.12$; interaction between weight and short-term bathing manipulation: $V=0.24, F_{2,24}$

$238=3.730, P=0.039, \eta_{p}{ }^{2}=0.24$; all test statistics for the omnibus test produced identical

239 outputs, hence only that for Pillai's trace is given here).

240 For two reasons we decided to refine our analysis such that the covariate

241 interaction could be negated. First, examination of the regression slopes revealed that the

242 interaction occurred primarily because of the differential effect of weight on the speed of

243 the subjects in each experimental group. Speed increased with weight for birds that had

244 bathed in the short-term, but speed decreased with weight for birds that had not bathed.

245 This interaction was unexpected and was probably an artefact given the lack of a

246 biologically realistic post hoc explanation for the interaction and the multiple covariate

247 interaction terms included in the full model. Second, we were primarily interested in the 
248 effect of treatment manipulations in this study. Hence, we used the Wilcox (Johnson-

249 Neyman) procedure to control for the heterogeneity in regression slopes (Wilcox 1987), a

250 test that establishes the limits of the covariate for which the treatment groups differ

251 (Quinn \& Keough 2002). The procedure revealed that between weights of 68.3 and $77.4 \mathrm{~g}$

252 there was no significant difference in the speed of subjects between the two groups. We

253 excluded any subjects from the analysis that fell outside of this range (leaving a sample

254 size of $\mathrm{N}=20$ ), then repeated the MANCOVA as per above. Both weight and the

255 weight*short term bathing manipulation interaction had nonsignificant effects in this new

256 model and hence were excluded to leave a minimal model that included only the

257 treatment factors. It showed that short-term access to bathing water was still the only

258 manipulation with a significant effect on flight speed and the number of strings hit (short-

259 term access to bathing water: $V=0.41, F_{2,15}=5.170, P=0.020 \eta_{p}^{2}=0.41$; long-term

260 access to bathing water: $V=0.25, F_{2,15}=2.449, P=0.120, \eta_{p}{ }^{2}=0.25$; interaction

261 between short-term and long-term access to bathing water: $V=0.24, F_{2,15}=2.374, P=$

$\left.2620.127, \eta_{p}^{2}=0.24\right)$.

263 Having demonstrated robustly that there was an effect of the short-term bathing

264 water manipulation, we subsequently included all subjects and conducted follow-up

265 ANOVAs on each dependent variable. These showed that there was no significant effect

266 of the bathing manipulations on either flight speed (short-term access to bathing water:

$267 F_{1,28}=2.13, P=0.155, \eta_{p}^{2}=0.07$; long-term access to bathing water: $F_{1,28}=0.32, P=$

$2680.575, \eta_{p}{ }^{2}=0.01$; interaction between short-term and long-term access to bathing water:

$269 F_{1,28}=0.27, P=0.606, \eta_{p}{ }^{2}=0.01$ ) or number of strings hit (short-term access to bathing

270 water: $F_{1,28}=1.98, P=0.171, \eta_{p}{ }^{2}=0.07$; long-term access to bathing water: $F_{1,28}=0.59$, 
$271 P=0.449, \eta_{p}^{2}=0.02$; interaction between short-term and long-term access to bathing

272 water: $F_{1,28}=1.31, P=0.262, \eta_{p}{ }^{2}=0.05$ ) when considered individually (see Figs 2 and

273 3: data from all subjects are plotted). This suggests that the effect of bathing depended on

274 the interaction of our two dependent variables.

275 To explore this possibility we undertook a discriminant function analysis to

276 establish how speed or the number of strings hit contributed to the ability to distinguish

277 subjects in the two short-term bathing experimental groups. The analysis revealed a

278 single discriminant function with a canonical $R^{2}=0.19$. This function significantly

279 differentiated between birds that had short-term access to bathing water or not $(\Lambda=0.81$,

$\left.280 \chi_{2}^{2}=6.12, P=0.047\right)$. The correlation between flight performance measures and the

281 discriminant function revealed that both measures loaded highly and positively on to this

282 function (speed: $r=0.947$; number of strings hit: $r=0.936$ ).

\section{DISCUSSION}

285 Effects of Short and Long-term Access to Bathing Water

286 Our results show that bathing in water in the $3 \mathrm{~h}$ prior to a flight test had a significant

287 impact on flight performance in starlings that had previously had their plumage disrupted

288 by catching and handling. Birds that had bathed in the short term tended to hit fewer

289 strings and fly more slowly through the obstacle course. Although this trend was not

290 statistically significant when each measure was examined individually, our results

291 suggest that the effect of short-term bathing is manifested in the trade-off between the

292 speed of escape and the need to avoid collisions. Indeed, the discriminant function

293 analysis shows that both speed and the number of collisions load highly on to the 

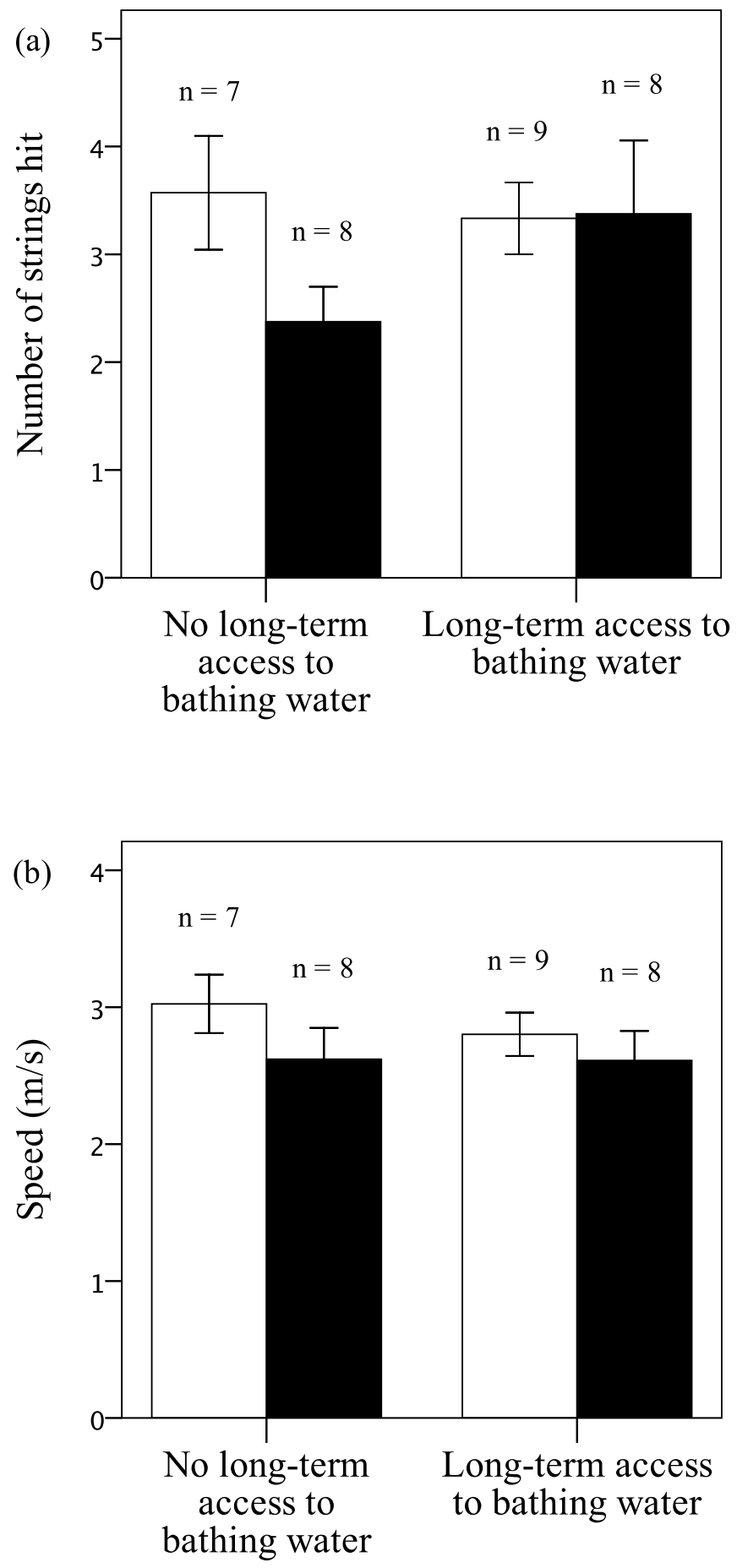

Figure 2. (a) Mean number of strings the subjects hit during flight and (b) mean speed , subjects through the obstacle course when they had short-term and long-term access to water baths. White bars represent subjects with no access to bathing water in the shortterm, black bars represent subjects with access to bathing water in the short term. Error bars represent $1 \mathrm{SE}$. 


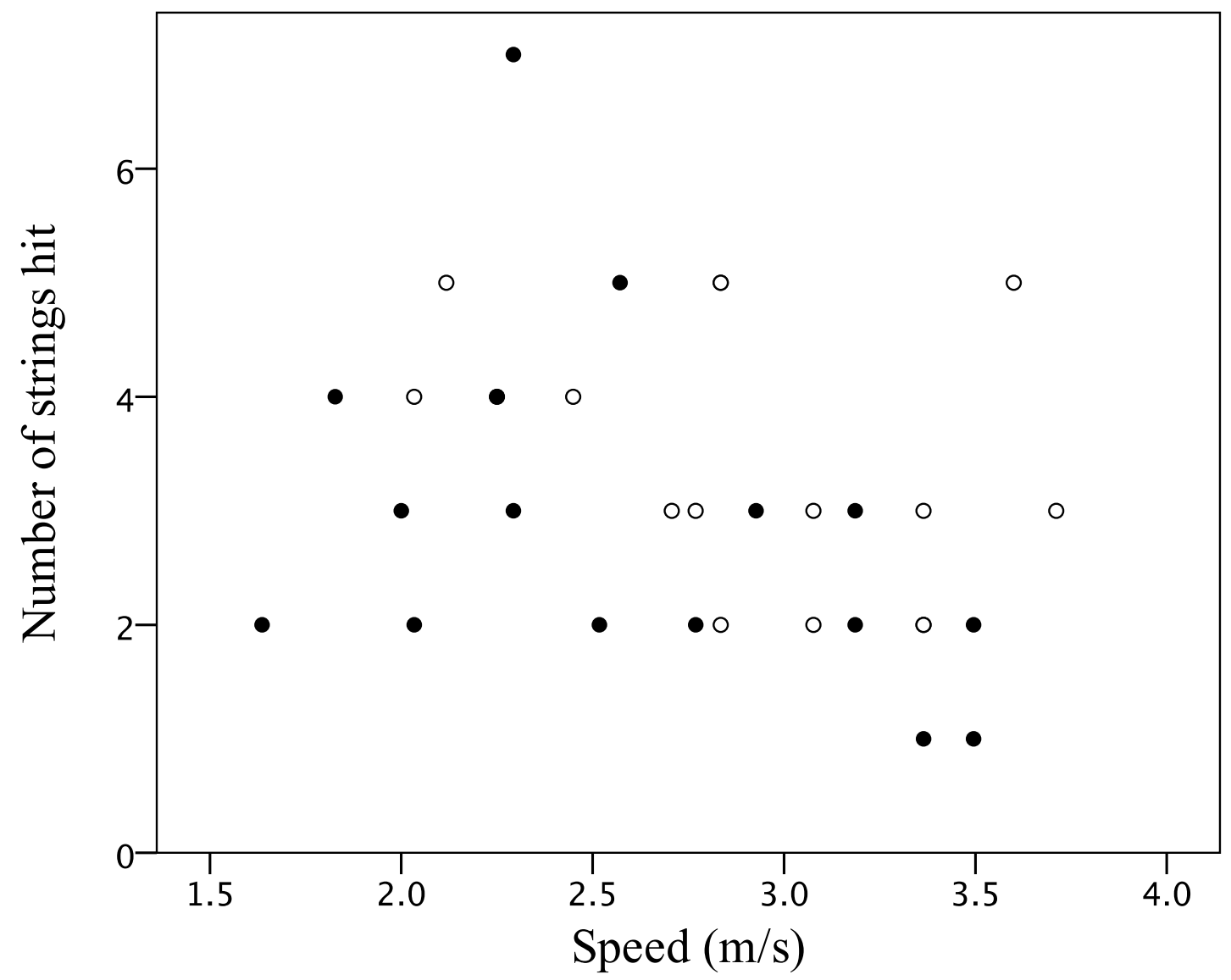

Figure 3. The relationship between speed through the aerial obstacle course and the number of strings hit. Filled circles represent the data from birds that had short-term access to bathing water. Open circles represent the data from birds that had no short-term access to bathing water. 
294 discriminant function that enables differentiation of the two short-term bathing

295 experimental groups. Additionally, this discriminant function had a canonical $R^{2}$ of 0.19 ,

296 suggesting that the short-term bathing manipulation caused at least a medium effect size

297 (Cohen 1992).

299 Relationship between Speed and Accuracy

300 Our results show that there was a (marginally nonsignificant) negative correlation

301 between flight speed and number of strings hit (i.e. there was a positive relationship

302 between speed and accuracy: see Fig. 3). However, the experimental manipulation

303 (providing bathing water immediately prior to the flight trials) decreased both flight

304 speed and the number of strings hit in equal measure (as indicated by the discriminant

305 function analysis). It therefore increased accuracy but seemingly at the expense of speed.

306 Below we discuss the implications of this finding within the context of other

307 experimental results.

308 In agreement with our findings, previous comparable experiments have generally

309 found that subjects that fly faster through an obstacle course have better accuracy in

310 avoiding strings (but see Evans et al. 1994 for a partially contradictory finding). Swaddle

$311 \&$ Witter (1998) found that there was no difference in flight speed in starlings with

312 varying wing asymmetry, but that more symmetrical birds hit fewer strings and tended to

313 be faster. Witter et al. (1994) found that manipulations of mass had no significant effect

314 on the time taken to complete an obstacle course, but that weighted birds hit more

315 obstacles. When a natural manipulation of mass was used (food deprivation) there was a

316 trend for lighter birds to be faster and hit fewer strings. Similarly, an experiment with 
317 house martins, Delichon urbica, found that birds with distal parts of the outer tail feathers

318 trimmed flew both faster and more accurately through an obstacle course (Matyjasiak et

319 al. 2004). Finally, Balmford et al. (2000) showed that artificially shortening the tail length

320 in golden-headed cisticolas, Cisticola exilis. resulted in decreased speed and more strings

321 hit, while increasing the tail length resulted in increased speed and accuracy.

322 We propose that within individuals there is a trade-off between flight speed and

323 flight accuracy. However, this trade-off is not apparent between individuals because

324 higher intrinsic flight performance ability is reflected in both higher speeds and improved

325 accuracy (in much the same way that people with larger houses also tend to own more

326 expensive cars). This is represented conceptually in Fig. 4a, which shows a speed-

327 accuracy trade-off within each individual (grey lines), but an overall positive correlation

328 of speed and accuracy between individuals (black line). The parallel light grey lines in

329 Fig. $4 \mathrm{~b}$ demonstrate the potential effect of our experimental manipulation, namely an

330 average decrease in speed and increase in accuracy. Figure $4 \mathrm{~b}$ also illustrates the two

331 possibilities for how the manipulation effected this change: either by altering the

332 perceived escape flight payoffs for the birds causing them to consider flight speed of less

333 importance than the reduction in collision risk (parallel dashed arrow in Fig. 4b); or by

334 causing some mechanical change in flight performance, altering the optimality trade-off

335 that each individual is able to make (oblique dashed arrow in Fig. 4b). These are not

336 mutually exclusive hypotheses; indeed it is hard to conceive of how a change in

337 perceived payoffs could occur without a proximate mechanical means (i.e. a change in

338 flight performance). 
(a)

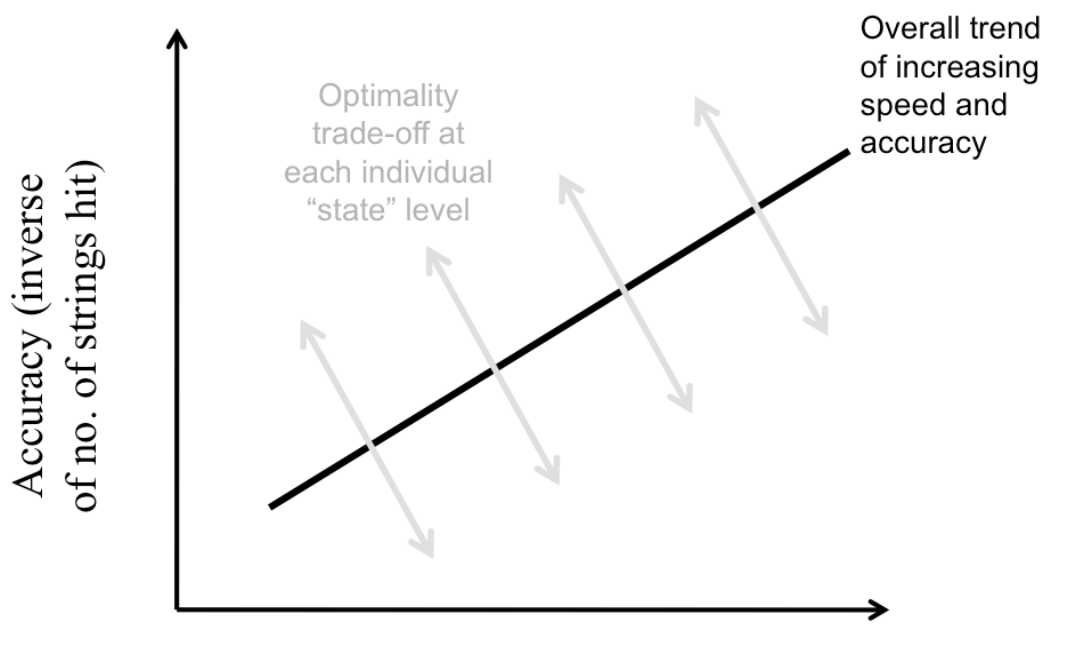

Speed

(b)

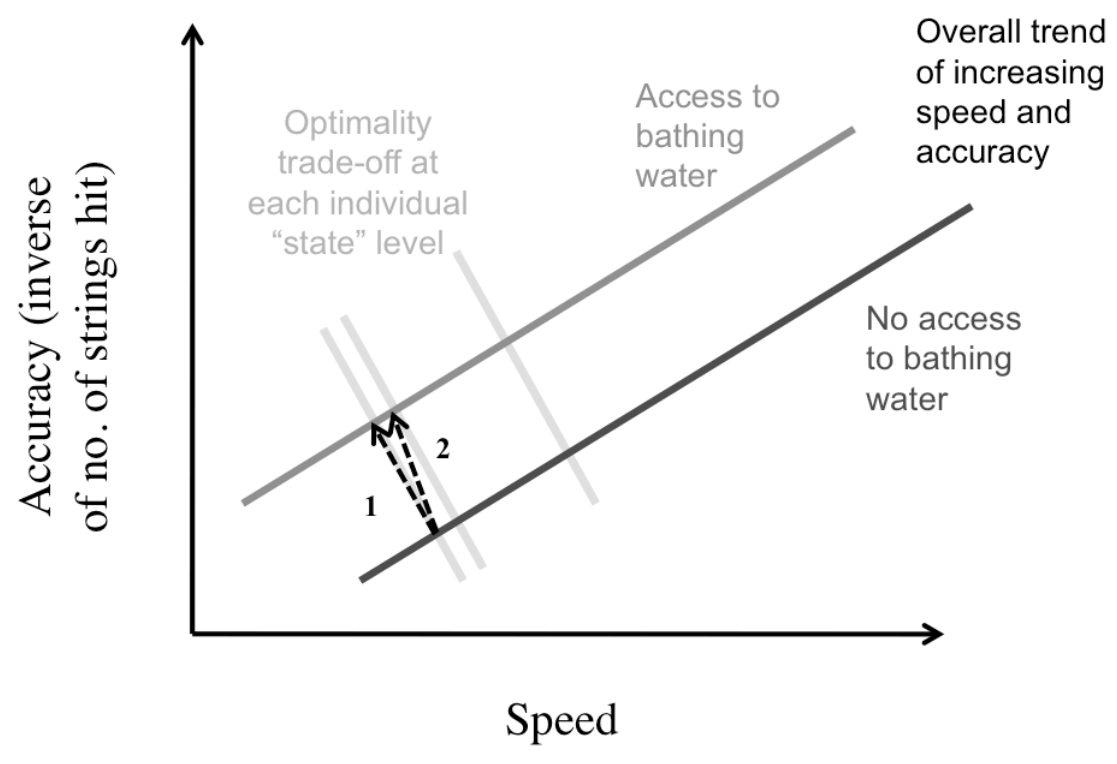

Figure 4. (a) A conceptual representation of the relationship between speed and accuracy. (b) A conceptual representation of the experimental manipulation effect. The dark grey line represents subjects that had no access to bathing water, the medium grey line represents subjects that did have access. The dashed black lines represent the proposed experimental effect: the parallel line (labelled 1) represents a change in the optimum of the same speed-accuracy trade-off; the oblique line (labelled 2) represents a change in mechanical flight performance causing a change in the achievable trade-off. 
340 flight performance: realignment of disrupted feather barbules (Healy \& Thomas 1973);

341 aiding the distribution of preen oil (Simmons 1964); enhancing feather flexibility/other

342 mechanical effects (Van Rhijn 1977); cleansing and removal of dirt (Slessers 1970; Van

343 Rhijn 1977); and thermoregulation (Thomas \& Robin 1977; Oswald et al. 2008). The

344 current data set unfortunately provides no means of distinguishing between these

345 competing hypotheses. On the basis of our anecdotal evidence on the increased eagerness

346 to bathe in birds that had been handled, we favour the explanation of realignment of

347 feather barbules. However, we must leave the question of mechanism for future

348 investigation.

350 Welfare Considerations in Captive Passerines

351 As a possible explanation for our results we suggest that the birds that had bathed in the

352 short term considered the speed of escape less salient than the need to avoid collisions.

353 This could be explicable if bathing had reduced perceived risk through a mechanical

354 improvement in flight performance. Flight manoeuvrability is considered to be an

355 important factor in birds' ability to escape from predators (Lima 1993; Witter et al.

356 1994), and reduced ability to deal with predation is reflected in an increased sensitivity to

357 predation cues and increased aversion to risk (Stankowich \& Blumstein 2005). Since

358 anxiety is the emotional process that deals directly with awareness and interpretation of

359 threatening stimuli (Lang et al. 2000), an increase in perceived risk of threats is likely to

360 increase anxiety levels (Loewenstein et al. 2001). In support of our argument, we have

361 evidence that starlings given access to bathing water subsequently show reduced 
362 sensitivity to cues of predation risk (conspecific alarm calls) (Brilot \& Bateson, 2012).

363 Additionally, captive starlings deprived of environmental enrichments, including water

364 baths, display evidence of a more negative affective state (Bateson \& Matheson 2007;

365 Matheson et al. 2008). Similarly, reduced dustbathing results in increased fear and stress

366 levels in junglefowl, Gallus gallus spadiceus, (Vestergaard et al. 1997) and domestic

367 chickens, Gallus gallus domesticus, (Campo and Muñoz 2001). Selective breeding for

368 low and high dustbathing lines in Japanese quail have also shown an inverse correlation

369 between dustbathing and susceptibility to fear (Gerken et al. 1988). We suggest that

370 anxiety caused by lack of water bathing or dustbathing might act as a mechanism for

371 increasing risk aversion to avoid potential threats that could not be dealt with in an

372 optimal fashion because of poor plumage condition. However, we accept that our data

373 provide only circumstantial evidence to support our discussion of the relationship

374 between bathing and anxiety.

375 In conclusion, we have shown that bathing alters the trade-off between escape

376 flight speed and accuracy in starlings, providing the first experimental demonstration of a

377 potential adaptive value of water bathing in birds. However, the proximate mechanism

378 for the effect of bathing (mechanical or perceptual) is unresolved. We hypothesise that

379 depriving birds of opportunities to bathe could result in increased anxiety because of a

380 compromised ability to escape from predators. 
384 We thank Chris Redfern, Tom Smulders and Michelle Waddle for technical help; Carel

385 ten Cate for useful discussions; Valentin Amrhein, Steve Oswald and several anonymous

386 referees for constructive comments on the manuscript. This work was supported by a

387 grant awarded to M.B. from the Biotechnology and Biological Sciences Research Council

388 (U.K.) [BB/E012000/1].

389

390 


\section{References}

392 Asher, L. \& Bateson, M. 2008. Use and husbandry of captive European starlings

393 (Sturnus vulgaris) in scientific research: a review of current practice. Laboratory

394 Animals, 42, 111-126.

395

396 Balmford, A., Lewis, M.J., Brooke, M.D., Thomas, A.L.R. \& Johnson, C.N. 2000.

397 Experimental analyses of sexual and natural selection on short tails in a polygynous 398 warbler. Proceedings of the Royal Society B, 267, 1121-1128.

400 Bateson, M. \& Matheson, S.M. 2007. Removal of environmental enrichment induces 401 'pessimism' in captive European starlings (Sturnus vulgaris). Animal Welfare, 16, 33-36. 402

403 Borchelt, P.L. \& Duncan, L. 1974. Dustbathing and feather lipid in bobwhite (Colinus 404 virginianus). Condor, 76, 471-472.

406 Brilot, B.O. \& Bateson, M. 2012. Water bathing alters threat perception in starlings. 407 Biology Letters, 8, 379-381.

409 Campo, J.L. \& Muñoz, I. 2001. Relationship between dustbathing activity and stress- or 410 fear-related responses in white, tinted, and brown egg breeds of chickens. Archiv für

411 Geflügelkunde, 65, 88-91. 
413 Clayton, D.H., Moyer, B.R., Bush, S.E., Jones, T.G., Gardiner, D.W., Rhodes, B.B.

414 \& Goller, F. 2005. Adaptive significance of avian beak morphology for ectoparasite

415 control. Proceedings of the Royal Society B, 272, 811-817.

416

417 Cohen, J. 1992. A power primer. Psychological Bulletin, 112, 155-159.

418

419 Cotgreave, P. \& Clayton, D.H. 1994. Comparative analysis of time spent grooming by

420 birds in relation to parasite load. Behaviour, 131, 171-187.

421

422 Cuthill, I. \& Guilford, T. 1990. Perceived risk and obstacle avoidance in flying birds.

423 Animal Behaviour, 40, 188-190.

424

425 Elowson, A.M. 1984. Spread-wing postures and the water repellency of feathers: a test of

426 Rijke's hypothesis. Auk, 101, 371-383.

427

428 Engqvist, L. 2005. The mistreatment of covariate interaction terms in linear model

429 analyses of behavioural and evolutionary ecology studies. Animal Behaviour, 70, 967-

430 971).

431

432 Evans, M.R., Martins, T.L.F. \& Haley, M. 1994. The asymmetrical cost of tail

433 elongation in red-billed streamertails. Proceedings of the Royal Society B, 256, 97-103. 434 
435 Gerken, M., Bamberg, H. \& Petersen, J. 1988. Studies of the relationship between

436 fear-related responses and production traits in Japanese quail (Coturnix coturnix

437 japonica) bidirectionally selected for dustbathing activity. Poultry Science, 67, 13634381371.

439

440 Hawkins, P., Morton, D.B., Cameron, D., Cuthill, I., Francis, R. \& Freire, R. 2001.

441 Laboratory birds: refinements in husbandry and procedures. Laboratory Animals, $\mathbf{3 5}$

442 (Supplement 1), 120-126.

443

444 Healy, W.M. \& Thomas, J.W. 1973. Effects of dusting on plumage of Japanese quail. 445 Wilson Bulletin, 85, 442-448.

446

447 Hedenström, A. 2003 Flying with holey wings. Journal of Avian Biology, 34, 324-327.

449 Lang, P.J., Davis, M. \& Öhman, A. 2000. Fear and anxiety: animal models and human 450 cognitive psychophysiology. Journal of Affective Disorders, 61, 137-159.

452 Lima, S.L. 1993. Ecological and evolutionary perspectives on escape from predatory 453 attack: a survey of North American birds. Wilson Bulletin, 105, 1-47.

455 Loewenstein, G.F., Weber, E.U., Hsee, C.K. \& Welch, N. 2001. Risk as feelings.

456 Psychological Bulletin, 127, 267-286. 
458 Matheson, S.M., Asher, L. \& Bateson, M. 2008. Larger, enriched cages are associated

459 with 'optimistic' response biases in captive European starlings (Sturnus vulgaris).

460 Applied Animal Behaviour Science, 109, 374-383.

461

462 Matyjasiak, P., Matyjasiak, J., de Lope, F. \& Möller, AP. 2004. Vane emargination of 463 outer tail feathers improves flight manoeuvrability in streamerless hirundines,

464 Hirundinidae. Proceedings of the Royal Society B, 271, 1831-1838.

465

466 Olsson, I.A.S. \& Keeling, L.J. 2005. Why in earth? Dustbathing behaviour in jungle and 467 domestic fowl reviewed from a Tinbergian and animal welfare perspective. Applied 468 Animal Behaviour Science, 93, 259-282.

470 Oswald, S.A., Bearhop, S., Furness, R.W., Huntley, B. \& Hamer, K.C. 2008. Heat 471 stress in a high-latitude seabird: effects of temperature and food supply on bathing and 472 nest attendance of great skuas Catharacta skua. Journal of Avian Biology, 39, 163-169. 473

474 Quinn, G.P. \& Keough, M.J. 2002. Experimental Design and Data Analysis for 475 Biologists. Cambridge: Cambridge University Press.

476

477 Redfern, C.P.F. \& Clark, J.A. 2001. Ringers' Manual. Thetford: British Trust for 478 Ornithology.

479 
480 Simmons, K.E.L. 1964. Feather maintenance. In: A New Dictionary of Birds (Ed. by

481 A.L. Thomson), pp. 278-286. New York: McGraw-Hill.

482

483 Slessers, M. 1970. Bathing behavior of land birds. Auk, 87, 91-99.

484

485 Stankowich, T. \& Blumstein, D.T. 2005. Fear in animals: a meta-analysis and review of 486 risk assessment. Proceedings of the Royal Society B, 272, 2627-2634.

488 Swaddle, J.P. \& Lockwood, R. 2003. Wingtip shape and flight performance in the 489 European starling Sturnus vulgaris. Ibis, 145, 457-464.

490

491 Swaddle, J.P. \& Witter, M.S. 1998. Cluttered habitats reduce wing asymmetry and 492 increase flight performance in European starlings. Behavioral Ecology and 493 Sociobiology, 42, 281-287.

494

495 Swaddle, J.P., Witter, M.S., Cuthill, I.C., Budden, A. \& McCowen, P. 1996. Plumage 496 condition affects flight performance in common starlings: implications for developmental 497 homeostasis, abrasion and moult. Journal of Avian Biology, 27, 103-111.

499 Thomas, D. H. \& Robin, A. P. 1977. Comparative studies of thermoregulatory and 500 osmoregulatory behaviour and physiology of five species of sandgrouse (Aves:

501 Pterocliidae) in Morocco. Journal of Zoology, 183, 229-249. 
503 Van Liere, D.W. \& Bokma, S. 1987. Short-term feather maintenance as a function of

504 dust-bathing in laying hens. Applied Animal Behaviour Science, 18, 197-204.

505

506 Van Rhijn, J.G. 1977. Processes in feathers caused by bathing in water. Ardea, 65, 126507147.

508

509 Vestergaard, K.S., Skadhauge, E. \& Lawson, L.G. 1997. The stress of not being able

510 to perform dustbathing in laying hens. Physiology \& Behavior, 62, 413-419.

511

512 Wilcox, R.R. 1987. Pairwise comparisons of J independent regression lines over a finite

513 interval, simultaneous pairwise comparisons of their parameters, and the Johnson-

514 Neyman procedure. British Journal of Mathematical and Statistical Psychology, 40, 80-

51593.

516

517 Witter, M.S., Cuthill, I.C. \& Bonser, R.H.C. 1994. Experimental investigations of

518 mass-dependent predation risk in the European starling, Sturnus vulgaris. Animal

519 Behaviour, 48, 201-222.

520

521 